\title{
Rules of Professional Conduct
}

\section{Maurizio Viezzi}

University of Trieste

\section{ABSTRACT}

All professional associations of interpreters and many institutions working with interpreters produce deontological documents (codes of ethics, codes of professional ethics, codes of conduct, standards of practice, etc.) containing principles and rules governing the interpreters' activity. Most of the principles and rules are straightforward and seem to be based on solid common sense. Others appear sound at first sight, but are inherently fuzzy, e.g. those concerning accuracy, or potentially controversial, e.g. those concerning confidentiality or impartiality. After briefly considering the concepts of ethics and professional ethics, and presenting the main features characterising deontological documents, the chapter discusses professional principles and rules with reference to over 20 documents published by a variety of bodies and institutions (judicial and healthcare institutions, professional associations of spoken language interpreters, sign language interpreters, court interpreters, healthcare interpreters, etc.). The principles and rules taken into consideration are: accuracy, confidentiality, impartiality, competence, professional conduct, role boundaries and professional development. The chapter ends with a proposal about how to structure training on this topic and with some suggestions for further reading.

Key words: deontological documents, professional rules, accuracy, impartiality, confidentiality 


\section{INTRODUCTION}

This chapter is devoted to rules of professional conduct in community or public service interpreting ${ }^{1}$ and is structured as follows: section 2 presents the concepts of ethics, professional ethics, deontology and standards of practice, and the deontological documents where those concepts are typically illustrated; in section 3 , the main professional principles and rules are discussed, with special attention paid to accuracy, confidentiality and impartiality; section 4 is about training and contains some suggestions on how to organise training activities with a view to raising awareness of professional rules and their importance; finally, a short list of publications is provided for those wishing to learn more about professional rules and other aspects of interpreting, in particular community or public service interpreting.

The aim of the chapter is to support the training of community or public service interpreters, not the training of intercultural mediators. Community interpreting and intercultural mediation are two completely different professions, to the point that in some or even most cases what intercultural mediators do (are required and expected to do) is something community interpreters should not do. ${ }^{2}$

The documents discussed in this chapter are documents referring to interpreting - interpreting in general (spoken language and sign language interpreting), but also community interpreting, healthcare interpreting and court interpreting. Such a scope may seem to exceed the remit of the TRAMIG project which is basically about spoken language interpreting (and intercultural mediation) in healthcare settings. If one looks at interpreting, though, one easily realises that there is a fundamental unity in what interpreters are called upon to do across the spectrum of their assignments. In a way, "interpreting is interpreting is interpreting": it is "source-text induced target-text production for a third party" as Neubert (2000, 10) would have it. ${ }^{3}$ That is why talking about interpreting as such makes sense and that is why reference to settings outside healthcare or even outside public service interpreting is here justified. ${ }^{4}$

1 For the purpose of this chapter, "community interpreting" and "public service interpreting" are regarded as synonymous as are "community interpreter" and "public service interpreter" (see also note 2 in Falbo, this volume).

2 See, for example, García-Beyaert et al.: "The interpreter may point to a possible cultural difference that interferes with effective communication, but should avoid providing cultural explanations of his or her own. To promote intercultural communication, the community interpreter should let the parties explore each other's cultural views themselves" (2015: 24) (emphasis added). Cultural explanations are one of the pillars of an intercultural mediator's activity.

3 Neubert was actually writing about translation, but the definition perfectly captures the essence of interpreting as well.

4 Whether court interpreting belongs to public service interpreting is a moot question. On the one hand, it has rules of its own, often enshrined in legislation, on the other, there is no doubt that justice (the administration of justice with all its structures, bodies and institutions) is a public service (see for example Jean 2010). 
There is no denying, though, that settings are crucially important. Interpreting is a service provided to particular people in a particular communicative situation (Gile 1995). The nature of the situation or event, the type of people involved and their mutual relationships have an impact on interpreters and their roles. Interpreting always entails barrier crossing, and language and culture may not be the only barriers that have to be negotiated - power, religion, emotions, etc. may be just as high or, more often than not, even higher and harder to cross. So, while interpreters are always asked to convey sense and establish communication, the conditions and circumstances under which they operate require resilience and the ability to adapt: interpreting during negotiations in a conflict area is not the same as interpreting in a hospital, interpreting for a gender violence victim is not the same as interpreting for a local government officer, etc. Furthermore, as will be seen, communication per se may not be the ultimate goal of the interpreters' activity.

For the rules discussed below, reference will be made to documents issued by professional associations and to documents issued by institutions that recruit interpreters and are users of interpreting services. It was deemed useful to compare and contrast the two as the former lay down a series of principles and norms that interpreters are committed to, whereas the latter lists a series of principles and norms that are imposed on interpreters. ${ }^{5}$ As will be seen, similarities prevail over differences. A training manual will also be occasionally mentioned and quoted. It should come as no surprise as there is an obvious connection between professional rules and training for a profession.

A final word on the importance of this topic for the training of trainers and therefore for the training of future interpreters. The principles, the codes, the norms provide food for thought - future trainers are invited to analyse and discuss them and are also invited to convey the outcome of their analyses and discussions to future interpreters to stimulate further reflection and debate, and raise awareness of the role played by professional rules. Future interpreters will thus acquire the tools they need to be able to make appropriate choices in their professional lives.

Principles, codes and norms, though, are not important just because they state what interpreters should or should not do, but because they also state what interpreters are allowed to do. While carrying out research for previous European projects, this author found that it is not uncommon for public service interpreters (including court interpreters) to assume a subordinate role - often they do not assert themselves and their professionalism, they do not insist on being granted adequate working conditions, they do not demand to be given whatever they need to be able to fulfil their tasks appropriately. As a result, there is often a "mismatch between the reality of the interpreters' working environment and the

5 Technically, the norms of a professional association are also imposed on members, but they are also, at the same time, the freely accepted expression of a common will. 
principles expressed in codes of ethics and standards of practice" (Pokorn and Mikolič Južnič 2020, 82). That is why deontological documents may play a crucial role with a view to empowering public service interpreters.

\section{DEONTOLOGICAL DOCUMENTS}

The word "ethics" is often used with regard to professions, professionals and their associations. In most cases it is not the right word as what is meant is actually "professional ethics". In general terms, ethics applies to people as human beings whereas professional ethics applies to people as professionals. The two may overlap, but do not coincide: based on ethics, a translator may decide not to sign a contract to translate Hitler's Mein Kampf; based on professional ethics a translator commits her/himself to translating it with the goal to produce what $\mathrm{s} / \mathrm{he}$ feels is the best possible translation. Baixauli-Olmos (2017) even suggests that there is a further step forward. When personal feelings and attitudes give way to official, collective norms, professional ethics is replaced by deontology: "while professional ethics refers to the desirable and optional good, and emanates from individual awareness and sensitivity, deontology stems from the collective agreement on what goods are required and on what rules practitioners are bound to follow. [...] deontology concerns norms" (Baixauli-Olmos 2017, 252); and deontological documents is the umbrella term he uses to refer to documents guiding the activity of professionals (ibid.).

Generally speaking, there are two types of such documents. The first is a "code" laying down binding principles and rules. Codes go by various names such as Code of Ethics (ATIA 2015), Code of Ethics and Professional Practice (ATA 2010), Code of Professional Conduct (ITI 2016), etc. A code of this type typically contains "a set of principles or values that govern the conduct of members of a profession while they are engaged in the enactment of that profession. It provides guidelines for making judgments about what is acceptable and desirable behaviour in a given context or in a particular relationship" (NCIHC 2004, 6). Along the same lines, the introduction to the Code of Professional Conduct of the Registry of Interpreters for the Deaf says that "a code of professional conduct is a necessary component to any profession to maintain standards for the individuals within that profession to adhere. It brings about accountability, responsibility and trust to the individuals that the profession serves" (RID 2005).

In principle, a professional code is only binding for the members of the professional association in question. To the extent to which it states principles that are considered universal, though, it becomes a set of norms and rules binding all current and future interpreters when practicing their profession, irrespective of their being or not being members of that association and irrespective of their having or not having proper qualifications. 
The type of code that has just been described is often accompanied by a different kind of document that tends to be "informative, longer and containing fairly specific guidelines" (Baixauli-Olmos 2017, 252). Again, different names are used (occasionally engendering some confusion): Standards of Practice (NCIHC 2005), Code of Conduct (AUSIT 2012), Commentary (ATA n.d.), etc. Documents of this kind serve to translate theory into practice: "Standards of practice are concerned with the 'hows' of performance as compared with codes of ethics that focus on the 'shoulds"' (NCIHC 2005, 1). In greater detail: standards of practice "are a set of guidelines that define what an interpreter does in the performance of his or her role, that is, the tasks and skills the interpreter should be able to perform in the course of fulfilling the duties of the profession. Standards describe what is considered 'best practice' by the profession and ensure a consistent quality of performance" (ibid.).

Codes issued by administrations and institutions address interpreter conduct from a different point of view, as is obvious for bodies that, unlike professional associations, are users of interpreting services. Some statements regarding the purpose and role of these codes clearly show their different nature. For example, according to the introduction to the Code of Ethics of the Wisconsin Court System, the purpose of a code of ethics (any code of ethics) is "to articulate a core set of principles to guide the conduct of a court interpreter and to educate judges in the level of conduct expected" (WCS 2014). ${ }^{6}$ The idea of client or customer education is not new, but when it comes from the users themselves it comes as a pleasant surprise. As regards the Wisconsin code itself, "it has been adopted by the Wisconsin Supreme Court to guide interpreter conduct while working in the courts of Wisconsin and to serve as a basis for interpreter education" (ibid.); ${ }^{7}$ mention has already been made of the connection between rules of professional conduct and training, but finding the concept in a document issued by an American State Court System is, again, rather surprising. The Wisconsin document also says that the purpose of the code is "to define the duties of interpreters and thereby enhance the administration of justice" (ibid.); ${ }^{8}$ and, along the same lines, "communication barriers must be removed as much as is reasonably possible so that [persons with limited proficiency in the English language] may enjoy equal access to justice" (ibid.). ${ }^{9}$ Similar concepts and wording may be found in the Code of Interpreter Ethics of the Illinois Supreme Court (ISC 2014), the Code of Ethics for Court Interpreters of the State of Mississippi (SoM 2011), the Code of Professional Conduct for Interpreters, Transliterators, and Translators of the New Jersey Supreme Court (NJSC 2016), etc. Privately and unofficially, interpreters may be

6 Emphasis added.

7 Emphasis added.

8 Emphasis added.

9 Emphasis added. 
seen as a necessary evil, but officially they are described as professional figures who, by making communication possible, contribute to the administration of justice, the enjoyment of rights, etc. - an important recognition and, at the same time, a great responsibility.

\section{PRINCIPLES AND RULES}

Interpreters' codes are all very similar, with relatively few principles that can be found in all of them - whether issued by professional associations or by administrations and institutions. The wording is sometimes different, some concepts may sometimes be dealt with under different headings, but by and large all codes deal with the same things - they state the same principles and the same norms. All of them have articles about accuracy, confidentiality, impartiality, etc. - which means that some principles are, actually, universal. They do not all say the same things about those principles, though - which means that this is an area where reflection and discussion have still a role to play to raise awareness of the complexity of the issues at stake and the diversity of points of view.

The main principles usually found in deontological documents will now be presented and discussed. More space and separate sub-sections will be devoted to accuracy, confidentiality and impartiality - three principles that are or may be to some extent controversial - with accuracy analysed in even greater detail on account of the complexity of the concept. The other principles appear more straightforward and will be covered in a single sub-section.

\subsection{ACCURACY}

With some inconsistencies and raising more than one doubt, all deontological documents agree on accuracy being one of the fundamental principles interpreters have to abide by: interpreting must be "accurate and complete" (e.g. NCIHC 2005, 1), "accurate and precise" (Home Office 2008, 3), etc.; there must be no additions or omissions or distortions (all of them); interpreters must interpret "accurately, completely and objectively" (ITIA 2009, 2), "faithfully, accurately and impartially" (ITI 2016: 5), "truly and faithfully" (NRPSI 2016, 4), "completely and truthfully" (NBTG 2014, 1), "with the greatest fidelity and accuracy" (ICTY 1999, 4), etc. The AUSIT Code of Ethics and Code of Conduct spell it out with great clarity. The fifth "general principle" of the Code of Ethics reads: "interpreters and translators use their best professional judgement in remaining faithful at all times to the meaning of texts and messages" (AUSIT 2012, 5); in the explanation that follows, a definition of accuracy is given: "accuracy for the purpose of this Code means optimal and complete message transfer into the target language preserving the content and intent of the source message or text without omission or distortion" (ibid.). The Code of Conduct simply adds that interpreters "do 
not alter, add to, or omit anything from the content of the source message", "acknowledge and promptly rectify" any interpreting mistakes, "ask for repetition, rephrasing or explanation if anything is unclear" (AUSIT 2012, 10) and little else. It looks very simple, but it is not.

The Code of Ethics for Community Interpreters of the Irish Translators' \& Interpreters' Association stipulates that interpreters should "emulate the inflections and intonations of the speaker" "and "reflect the person's way of speaking as accurately as possible" (ITIA 2009, 3). "Emulate the inflections and intonations": can it be done across languages?

The Irish code also states that interpreters should not "emulate the gestures made by the speakers" (ITIA 2009, 3); similarly, the Wisconsin code states that the emotional emphasis of the speaker should be conveyed "without reenacting or mimicking the speaker's emotions, or dramatic gestures" (WCS 2014) which seems to mean that emotions and gestures should be "translated" into words. Actually, this is exactly what the NCIHC code says: "interpreters should convey the meaning of those gestures, body language, and tone of voice that add significantly to the content of the message, especially when these might not be noted or might be misunderstood by the other party" (NCIHC 2004, 13). "Conveying the meaning of gestures, etc." means saying something that has not been said: is this compatible with the no-addition tenet?

On the other hand, it is not uncommon for codes to say that interpreters must convey the content and intent of the speaker's message (AUSIT 2012, 5) or its content and spirit (NCIHC 2004, 3; RID 2005, 3) or the speaker's intention (NBTG $2014,1)$ which is perfectly in line with one of the fundamental tenets of conference interpreting and in particular with the interpretive theory of translation (Seleskovitch and Lederer 1984), but perhaps at odds with the (traditional) attitude aiming at limiting to a minimum the interpreter's room for manoeuvre in the name of literalism.

The wording used for the accuracy rule is often, but not always, categorical. In the code of ethics of the National Council on Interpreting in Health Care (NCIHC), the accuracy rule reads as follows: "the interpreter strives to render the message accurately, conveying the content and spirit of the original message, taking into consideration its cultural context" (NCIHC 2004, 3). Two points stand out: the verb to strive and the reference to the cultural context, both of which suggest that interpreting is not an easy and simple automatic/mechanical operation as someone might be tempted to believe. ${ }^{10}$ The NCIHC code is based on three core

10 In the framework of previous projects (AVIDICUS 3 n.d., TransLaw n.d.), this author carried out a number of interviews and still remembers a judge saying: "why would they need to prepare for an assignment? Interpreters only have to translate". 
values: ${ }^{11}$ the first is beneficence and will be discussed below; the second is fidelity and is obviously related to accuracy: "interpreters make what amounts to a vow to remain faithful to the original message as they convert utterances from one language into another without adding to, omitting from, or distorting the original message" (NCIHC 2004, 8-9). ${ }^{12}$ The third core value of the NCIHC code, respect for the importance of culture and cultural differences, is also related to accuracy: interpreters must understand the impact of culture on the way in which health issues are experienced, its impact on communication about health issues; they must understand the way in which "alternative views of the world can lead to critical misunderstandings and miscommunication" ( NCIHC 2004, 9). They have to understand "not only the words that are being used but also the underlying, culturally-based propositions that give them meaning in the context in which they are spoken" (NCIHC 2004, 14). Accuracy, therefore, is something more than what can be achieved by using readily-available dictionary equivalents. In the words used in the Guidelines of the New South Wales Health Care Interpreter Services, "interpreters make appropriate linguistic and cultural decisions in order to convey all aspects of the message" (NSW HCIS 2014, 11). ${ }^{13}$

Accuracy is crucially important, ${ }^{14}$ but of course interpreting per se is first and foremost about communication. In this regard, the RID code states that interpreters

11 The same core values are shared by the Code of Ethics and Standards of Practice for Interpreters of the Winnipeg Regional Health Authority (WRHA 2015).

12 The outcome, though, can never be taken for granted: "what the speaker means and what the listener understands are not always aligned. [...] many concepts and expressions lack precise equivalents in other languages, yet the interpreter has to come up with linguistic solutions on the spot. As a result, interpreters can only strive for accuracy" (García-Beyaert et al., 2015, 13, emphasis added). García-Beyaert et al. is not a deontological code, but a text "based on a critical distillation and selection of principles and standards included in codes of ethics for interpreters around the world" whose aim is to "support the education and training of community interpreters" (García- Beyaert et al. 2015, 4). Perhaps its most innovative contribution to the field is the concept of communicative autonomy defined as "the capacity of each party in an encounter to be responsible for and in control of his or her own communication" (ibid.), a fundamental precept "that should underlie every aspect of the development and practice of community interpreting” (ibid.).

13 The cultural dimension and cultural barriers are of course never far away from centre stage in the codes. All of them deal with them, more or less extensively. Just a few examples: "the interpreter takes into account social and cultural differences" (NBTG 2014, 1.); the interpreter may "alert the parties to a possible missed cultural reference or inference" (NRPSI 2016, 54); interpreters are "committed to providing quality service in a respectful and culturally sensitive manner" (AUSIT 2012, 4), etc.

14 Accuracy is always important, and in some settings even more so than in others. In court, for example: "it is important to remember that the judge and/or jury will be relying entirely on the interpreted version of testimony to draw conclusions about the credibility of witnesses and the relative weight of testimony" (JCC 2013, 3); or in healthcare: "interpreters need to be mindful that any piece of information may be an important data source. To omit or distort any of the information could, therefore, result in serious clinical consequences" (NCIHC 2004, 13). 
"render the message faithfully [...] using language most readily understood by consumers" (RID 2005, 3) and, according to NAJIT, "the rendition should sound natural in the target language" (NAJIT n.d.). Again, a fundamental principle in conference interpreting, but one that is not shared by all deontological documents, particularly in the judicial field where there are texts stating that interpreters must "never alter the register, or level of language, to make it easier to understand or more socially acceptable" (JCC 2013, 7) or that "under no circumstances should an interpreter become involved in the conversion of units of measurement or currency from one system to another" (JCC 2013, 5) - two quotations that might even lead one to conclude that, at least for the Judicial Council of California, the interpreting goal is not communication. Yet, the same body, in the same document, says that "the primary focus in interpreting is to convey the meaning, not individual words" (JCC 2013, 9): but how can one convey meaning if the words used are not understood?

Inconsistencies and questionable statements are not uncommon in documents that are not produced by interpreters but by professionals in other fields who do not always realise that the interpreting process is much more complex than it appears - they would never use a verb such as strive and would never imagine that even an apparently crystal clear statement such as "the interpretation process involves converting a message from one language (source language) into an equivalent message in another language (target language)" (WRHA 2015, 4) raises more questions than it answers (as Translation Studies history shows).

Things are changing, though. While some may still equate accuracy with literalism, particularly in legal settings (Mikkelson 2008: 82), there have been considerable steps forward. In the commentary to the "accuracy and completeness" rule, for example, Mississippi's Code of Ethics for Court Interpreters states that "verbatim, 'word for word,' or literal oral interpretations are not appropriate when they distort the meaning of the source language" (SoM 2011, 2).$^{15}$ The same point is made in the codes of Illinois (ISC 2014) and Wisconsin (WSC 2014); and the latter adds a significant point by requiring interpreters to reproduce in the target language "the closest natural equivalent of the source language message". It is a concept developed by Eugene Nida (1964) to overcome literalism, one which again may raise doubts as it would seem to imply that for any source language message (or elements thereof) there is one solution that might objectively be regarded as the best. Questionable, to say the least.

Of course, communication is complex and communication across languages even more so - it does not lend itself to categorization or to a binary-code kind of logic (yes/no; right/wrong, etc.), not to mention the inescapable subjective

15 As is obvious, documents issued by professional associations of interpreters reject word-forword (translation and) interpreting (e.g. see ATA n.d., 1). 
element. According to the Professional Standards and Ethics for California Court Interpreters, "when rendering a simple 'yes' as 'yes, I did', the interpreter is adding information that was not contained in the original response" (JCC 2013, 4): true, there is no reason why the interpreter should not confine her/himself to a 'yes', but is this really an example of inaccuracy? Has any piece of information actually been added? Perhaps a more lenient approach would be needed when dealing with as fuzzy a concept as accuracy. Is bonjour an accurate translation of good morning? Is good morning an accurate translation of bonjour? And while one can easily agree that translating France with l'Hexagone may not be appropriate, is the reverse also true? How can absolute accuracy (faithfulness, truth, etc.) be demanded when not only is the concept fuzzy per se, but it is so easy to realise that translating/interpreting basically - perhaps inevitably - means saying almost the same thing as Umberto Eco (2003) would have it?

A final quotation may serve as the starting point for some concluding remarks on accuracy. The Code of Ethics for Interpreters and Translators of the International Criminal Tribunal for the Former Yugoslavia devotes article 10 to accuracy. Paragraph 1, entitled Truth and completeness, stipulates that interpreters "shall convey with the greatest fidelity and accuracy, and with complete neutrality, the wording used by the persons they interpret" and "shall convey the whole message, including [...] any non-verbal clue" (ICTY 1999, 4). The wording, the message and any non-verbal clue: is it not too much? Not to mention neutrality that will be briefly considered below. Even leaving aside inconsistencies, contradictions and the many ill-defined notions, what is demanded of interpreters really seems to be too much. In particular for interpreters who, as is not uncommon in community settings, do not have a high level of proficiency in one of the two languages. Asking them to convey the speaker's tone, register, nuances, ambiguities, etc. means, in some or many or most cases, asking them to do something they simply cannot do.

\subsection{CONFIDENTIALITY}

Confidentiality is "the only ethical principle that appears to be a universal requirement to the interpreting profession" (García-Beyaert et al. 2015,10) and is covered by all deontological documents. It appears as one of the 'over-arching' principles of NRPSI's Code of Professional Conduct (2016) and at the top of the list of principles making up the Code of Ethics for Interpreters in Health Care of the National Council on Interpreting in Health Care (NCIHC 2004). In the AUSIT Code, one sentence is enough to spell out the principle: "Interpreters and translators maintain confidentiality and do not disclose information acquired in the course of their work" (AUSIT 2012, 5).

It is not an absolute principle, in that there may be derogations, for example when it is the law that demands it: "the duty of confidentiality shall not apply where disclosure is required by law" (NRPSI 2016, 3); or when a crime is involved: "in the event that an interpreter becomes aware of information that indicates probable 
imminent harm to someone or relates to a crime being committed during the course of the proceedings, the interpreter should immediately disclose the information to the presiding judge" (WCS 2014). The two cases are straightforward, but circumstances may sometimes be much more complex, in healthcare for example, with the interpreter having to face difficult choices.

According to the NCIHC code, "situations in which there is a serious possibility that withholding information will result in harm to the patient or to others can be an exemption to the principle of confidentiality" (NCIHC 2004, 11) - confidentiality is still required but only "in relation to those outside the treating team" (NCIHC 2004, 12). Any derogation from confidentiality must be based on beneficence, one of the core values of the NCIHC and WRHA codes: "a central value of the health care interpreting profession is the health and well-being of the patient. This is a core value that is shared with other health care professions" (NCIHC 2004, 8). Similarly, the WRHA code says that "health interpretation extends beyond simple message conversion and conveyance. It is grounded in the best interest of the patient. [...] both the provider and the interpreter are concerned with the patient's health and well-being" (WRHA 2015, 4). The fact that this quotation comes from a document issued by a service provider is, of course, rather significant. Needless to say, choosing whether to violate confidentiality can never be easy, but "interpreters have an ethical obligation to deal with this fine line and make a conscious choice that supports the well-being of the patient" (NCIHC $2004,10)$. The issue is controversial, but the logic chain "the interpreter's goal is the patient's well-being - confidentiality may harm the patient - the interpreter derogates from confidentiality" is to some extent convincing, though probably not universally shared.

A further case - interesting and surprising - of exemption from the principle of confidentiality is provided for by the Wisconsin Court System code: "interpreters shall not publicly discuss, report, or offer an opinion concerning a matter in which they are or have been engaged [...] except to facilitate training and education", in which case they are allowed to divulge "only so much information as is required to accomplish this purpose" (WCS 2014). It is a further example of the importance the Wisconsin Court System attaches to training and education.

\subsection{IMPARTIALITY}

Impartiality is also one of the fundamental tenets of an interpreter's activity: "interpreters [...] observe impartiality in all professional contacts. Interpreters remain unbiased throughout the communication exchanged between the participants in any interpreted encounter" (AUSIT 2012, 5). Just like confidentiality, it appears in all codes and is a rather straightforward concept: interpreters do not take sides and "do not allow bias to influence their performance" (ibid.). Unlike confidentiality, though, it can be easily and inadvertently violated. For whatever reason, interpreters may be inclined to like/dislike or support/oppose one or more 
participants, and their feelings may creep into their words, attitude, behaviour or facial expressions. Needless to say, all this should be avoided: as García-Beyaert et al. say, "community interpreters cannot be neutral in their feelings. Yet they can make every effort to be impartial in their behavior" $(2015,15)$. It is not easy, particularly in emotionally charged situations.

The word "neutral" used by García-Beyaert et al. and the word "neutrality" used in the ICTY code (see section 3.1) deserve a brief comment. Neutral/neutrality are not synonymous with impartial/impartiality. It is not just a matter of neutral feelings: for the very fact that they do participate in the event, interpreters have an impact on it. It is recognised in the code of the Dutch Association of Sign Language Interpreters: the interpreter "exerts influence even by her presence on the course of the communication in the assignment" (NBTG 2014, 2). Neutrality can therefore never be expected for the simple reason that it is impossible.

On the other hand, not only can impartiality be expected, but the principle would seem to be absolutely binding, with no possible derogations. Yet, exceptions may be found in healthcare interpreting codes. The NCIHC code, in line with all other codes, states that "the interpreter strives to maintain impartiality and refrains from counseling, advising or projecting personal biases or beliefs" (NCIHC 2004, 3), but it adds that "when the patient's health, well-being, or dignity is at risk, the interpreter may be justified in acting as an advocate" (ibid.). Once again, taking care of the patient's health is regarded as the overriding principle prevailing over all others, including confidentiality and impartiality. Advocacy is explicitly rejected by all codes and the NCIHC itself appears to be aware of the devastating consequences potentially brought about by advocacy supplanting impartiality, yet it supports it as a means to achieve a greater goal: "the act of advocacy should derive from clear and/or consistent observations that something is not right and that action needs to be taken to right the wrong. On a deep level, advocacy goes to the heart of ethical behavior for all those involved in health care - to uphold the health and wellbeing (social, emotional and physical) of patients and ensure that no harm is done" (NCIHC 2004, 20).

The Code of Ethics of IMIA also opens the doors to advocacy, but only as a way to overcome cultural barriers: "Interpreters will engage in patient advocacy and in the intercultural mediation role of explaining cultural differences/practices to health care providers and patients only when appropriate and necessary for communication purposes, using professional judgment" (IMIA 2006).

Curiously enough, in the AUSIT's codes norms are included under the impartiality heading that (would seem to) belong elsewhere: "[interpreters] do not soften, strengthen or alter the messages being conveyed" (AUSIT 2012, 5) (which is something probably pertaining to accuracy), and "[interpreters] frankly disclose all conflicts of interest" (AUSIT 2012, 9) (which appears under Impartiality in the Code of Conduct and under Professional conduct in the Code of Ethics). It is 
an example of how difficult it is to draw a line between principles that are often intertwined.

\subsection{OTHER PRINCIPLES}

The other principles found in deontological documents are much less controversial, or not controversial at all, and seem to be all based on solid common sense as will be seen in this short overview which is limited the most significant.

3.4.1 Competence. "Interpreters [...] only undertake work they are competent to perform in the languages for which they are professionally qualified through training and credentials" (AUSIT 2012, 5). The AUSIT codes refer to qualifications as they are professional codes that are binding for the association's members. The principle, though, is universal in that all interpreters (whether qualified or not) should only accept tasks they are or feel able to fulfil: "interpreters will refrain from accepting assignments beyond their professional skills, language fluency, or level of training" (IMIA 2006). Needless to say, this requires some level of self-awareness and also the readiness to turn down the opportunity to earn a fee when the assignment is or appears to be beyond one's abilities.

Most, if not all, codes issued by Judicial administrations include an article devoted to the "representation of qualifications" which, in fact, may actually be seen as an official proof of competence.

3.4.2 Professional conduct. Whether trained/qualified or not, interpreters are supposed to act in a professional manner. All codes deal with this principle which, understandably, covers a very wide area and several aspects. For example, preparation: "the responsibility of being properly prepared for interpreting assignments" (WCS 2014). To this end, interpreters are encouraged to obtain information, documents and whatever may be needed to familiarise themselves with the topic, the event, etc. Another aspect related to professionalism has to do with working conditions: interpreters should ensure "that the conditions under which they operate facilitate communication" (ICTY 1999). ${ }^{16}$ Then, in performing their duties, interpreters behave professionally when they take care of communication between the parties, for example by "coordinating or managing turn-taking in order to make the communication process flow smoothly and minimise disruptions" (NSW HCIS 2014, 11) ${ }^{17}$ they also behave professionally when they "use the first person" (AUSIT 2012, 14); when they encourage "participants to address

16 To be able to prepare and ensure ideal working conditions interpreters must count on the attitude of organisers, institutions, participants, etc. and their willingness and readiness to meet the interpreters' needs, something which may require a good deal of customer education.

17 It should be noted, though, that playing such a coordinating role may be very difficult or even impossible in certain settings, e.g. in court where unobtrusiveness on the part of the interpreter is called for (WCS 2014; NAJIT n.d., etc.) 
each other directly" (ibid.); when they are transparent as to their role at any point in the communication process: for example, "when asking for clarification, an interpreter says to all parties, 'I, the interpreter, did not understand, so I am going to ask for an explanation"' (NCIHC 2005, 5); they finally behave professionally when they show respect for all parties (WSL 2015; RID 2005, etc.) and professional detachment (AUSIT 2012; WCS 2014). Other obvious requirements include respect for the dress code and punctuality.

3.4.3 Clarity of role boundaries. The Wisconsin Code of Ethics is adamant: "interpreters shall limit themselves to interpreting or translating" (WCS 2014). The explanation accompanying this principle in the AUSIT codes is very clear as to what it actually means: "Practitioners do not, in the course of [their] duties, engage in other tasks such as advocacy, guidance or advice" (AUSIT 2012, 6). So, advocacy is forbidden (but see above in the sub-section devoted to impartiality) and other activities outside interpreting are forbidden as well. A significant example in this respect may be found in the Wisconsin code (where the term used is scope of practice): "Interpreters may translate language on a form for a person who is filling out the form, but should not explain the form or its purpose for such a person" (WCS 2014). Ideally, interpreters should have no contacts whatsoever with the people for whom they are interpreting to avoid inadvertently or deliberately exceeding the limits of their role.

3.4.4 Professional development. Finally, all deontological documents stress the importance and the duty (as well as the need) for interpreters to "improve their skills and knowledge" (WCS 2014). This includes upgrading their cultural understanding and keeping up "with the technological advances pertinent to their practice" (AUSIT 2012, 6) and even keeping themselves "informed about new trends and developments and the results of research in the field to improve their competence and practice" (AUSIT 2012, 12). The IMIA code also stresses the importance of maintaining ties with relevant professional organizations in order to be up-to-date with the latest professional standards and protocols" (IMIA 2006). In this regard there is no difference between interpreters and all other professionals: lifelong learning is the only way to be able to fulfil one's professional duties throughout one's career. 


\section{ACTIVITIES}

Training activities may be divided into two parts, the first devoted to theory and the second to practice. In the first part trainers present the concepts of ethics and professional ethics, the nature and purpose of deontological documents and the main professional rules. One code may be used as the main source, with constant reference to other codes to explore alternative points of view. Q\&A sessions and focused discussions are then organised to give trainees the opportunity to really understand the spirit and purpose of the codes and their rules as well as their implications for the interpreters' work and the possible consequences of any violation. Some time can also be reserved to the presentation and discussion of personal experiences involving deontological issues.

The second part consists of role-plays where trainees are faced with deontologically-challenging situations requiring problem-solving and decision-making skills. ${ }^{18}$ The role-plays are followed by discussion of the choices made by the trainees playing the interpreters and their repercussions on the interpreter-mediated interactions. ${ }^{19}$

As an alternative option, some role-play sessions could also be organised before the first part - designed and conducted as described above, but with no discussion or debriefing/assessment. They should be video-recorded and only shown at the end of the second part. This will enable the class to compare and contrast the trainee interpreters' performances delivered before and after the theory lessons.

Whatever the option, trainers should devote as much time as possible to discussion. Principles and rules must not be learnt by heart, but understood, adhered to and, when the time comes, naturally implemented.

18 Some examples are given by Mikkelson: "The scenarios can range from straightforward situations that test the students' understanding of concepts such as confidentiality and impartiality (e.g., a defendant asking the interpreter what she thinks of his defence counsel) to more complicated circumstances that pose difficult linguistic and/or ethical conundrums (e.g., kinship terms for which there is no equivalent, attitudes about sex roles that differ greatly, or gestures that are easily misunderstood" (Mikkelson 2008, 92). A number of situations that could be easily and fruitfully reproduced in role-plays can also be found in García-Beyaert et al. (2015).

19 On role-plays and their stages, from design to debriefing/assessment, see Falbo (this volume). 


\section{FURTHER READING}

Hale, Sandra Beatriz. 2007. Community Interpreting. Basingstoke-New York: Palgrave Macmillan.

An extensive discussion of community interpreting from theory to practice, from codes of ethics to research, from practitioners' views to training.

Kalina, Sylvia. 2015. "Ethical challenges in different interpreting settings". MonTI Special Issue 2: 63-86.

A thorough discussion of differences and similarities between ethical/deontological issues confronting interpreters in multiple settings.

Ozolins, Uldis. 2014. "Descriptions of interpreting and their ethical consequences”. FITISPos International Journal 1, no. 1: 23-41.

A well-documented analysis of interpreting and the interpreter's role across modes and settings, with a reflection on ethics and ethical responsibility.

Valero Garcés, Carmen, and Anne Martin, eds. 2008. Crossing Borders in Community Interpreting. Amsterdam-Philadelphia: John Benjamins.

A wide-ranging volume that has become a classic. The chapters' focus is the interpreter's role in a variety of settings. 


\section{BIBLIOGRAPHY}

ATA (American Translators Association). 2010. Code of Ethics and Professional Practice. Accessed August 12, 2020. https://www.atanet.org/governance/ code_of_ethics.php.

ATA (American Translators Association). n.d. Code of Ethics and Professional Practice. Commentary. Accessed August 12, 2020. https://www.atanet.org/ governance/code_of_ethics_commentary.pdf.

ATIA (Association of Translators and Interpreters of Alberta / Association des Traducteurs et Interprètes de l'Alberta). 2015. Code of Ethics. Accessed August 12, 2020. https://atia.ab.ca/code-of-ethics/.

AUSIT (Australian Institute of Interpreters and Translators). 2012. Code of Ethics and Code of Conduct. Accessed August 10, 2020. https://ausit.org/wp-content/uploads/2020/02/Code_Of_Ethics_Full.pdf.

AVIDICUS 3. n.d. http://wp.videoconference-interpreting.net/?page_id=154.

Baixauli-Olmos, Lluís. 2017. "Ethics codes as tools for change in public service interpreting: symbolic, social and cultural dimensions.” JoSTrans. The Journal of Specialised Translation 28: 250-272. Accessed August 13, 2020. https:// www.jostrans.org/issue28/art_baixauli.php.

Eco, Umberto. 2003. Dire quasi la stessa cosa. Milano: Bompiani.

García-Beyaert, Sofía, Marjory A. Bancroft, Katharine Allen, Giovanna Carriero-Contreras, and Denis Socarrás-Estrada, eds. 2015. Ethics and Standards for The Community Interpreter. An International Training Tool. Accessed August 18, 2020. https://ddd.uab.cat/pub/recdoc/2015/218104/Garcia-Beyaert_et_al_2015_TCii_Ethics_and_Standards.pdf.

Gile, Daniel. 1995. Basic Concepts and Models for Interpreter and Translator Training. Amsterdam-Philadelphia: John Benjamins.

Home Office - UK Visas \& Immigration. 2008. Code of Conduct for the Home Office Registered Interpreters. Accessed August 20, 2020. https://assets.publishing.service.gov.uk/government/uploads/system/uploads/attachment_data/ file/454473/Code_of_conduct_17_08_15.pdf.

ICTY (= United Nations - International Tribunal for the Prosecution of Persons Responsible for Serious Violations of International Humanitarian Law Committed in the Territory of Former Yugoslavia since 1991). 1999. The Code of Ethics for Interpreters and Translators employed by The International Criminal Tribunal for the Former Yugoslavia / Code de déontologie pour interprètes et traducteurs employés par le Tribunal International pour l'ex-Yougoslavie. Accessed August 14, 2020. https://www.icty.org/x/file/Legal\%20Library/Miscellaneous/it144_codeofethicsinterpreters_en.pdf. 
IMIA (= International Medical Interpreters Association). 2006. Code of Ethics. Accessed August 13, 2020. https://www.imiaweb.org/code/.

ISC (= Illinois Supreme Court). 2014. Code of Interpreter Ethics. Accessed August 14, 2020. https://courts.illinois.gov/civiljustice/languageaccess/Illinois_ Code_of_Interpreter_Ethics.pdf.

ITI (Institute of Translation and Interpreting). 2016. ITI Code of Professional Conduct. Accessed August 11, 2020. https://www.iti.org.uk/about-iti/professional-standards.html.

ITIA (Irish Translators' \& Interpreters' Association). 2009. Code of Ethics for Community Interpreters. Accessed August 14, 2020. https://www.translatorsassociation.ie/wp-content/uploads/2017/03/Code-of-Ethics-for-Community-Interpreters.pdf.

JCC (= Judicial Council of California). 2013. Professional Standards and Ethics for California Court Interpreters. Fifth Edition (first edition 2008). Accessed August 19, 2020. https://www.courts.ca.gov/documents/CIP-Ethics-Manual.pdf.

Jean, Jean-Paul. "Justice as a public service". 2010. 6th CEPEJ Newsletter. Accessed August 23, 2020. https://rm.coe.int/justice-as-a-public-service-jean-pauljean-prosecutor-court-of-appeal-/168078e545.

Mikkelson, Holly. 2008. "Evolving views of the court interpreter's role: Between Scylla and Charybdis". In Crossing Borders in Community Interpreting: Definitions and dilemmas, edited by Carmen Valero Garcés and Anne Martin, 81-97. Amsterdam-Philadelphia: John Benjamins. Accessed August 17, 2020. https://doi.org/10.1075/btl. Also available at https:/acebo.myshopify.com/ pages/evolving-views-of-the-court-interpreter-s-role-between-scylla-andcharybdis.

NAJIT (= National Association of Judiciary Interpreters \& Translators). n.d. Code of Ethics and Professional Responsibilities. Accessed August 17, 2020. https:// najit.org/wp-content/uploads/2016/09/NAJITCodeofEthicsFINAL.pdf.

NBTG (NEDERLANDSE BEROEPSVERENIGING TOLKEN GEBARENTAAL $=$ DUTCH ASSOCIATION FOR SIGN LANGUAGE INTERPRETRS. 2014. Code of Ethics for Sign Language Interpreters. Accessed August 21, 2020. http://www.nbtg.nl/sites/default/files/1403\%20Code\%20 of\%20Ethics.pdf

NCIHC (National Council on Interpreting in Health Care). 2004. A National Code of Ethics for Interpreters in Health Care. Accessed August 24, 2020. https://www.ncihc.org/assets/documents/publications/NCIHC\%20National\%20Code\%20of\%20Ethics.pdf. 
NCIHC (National Council on Interpreting in Health Care). 2005. National Standards of Practice for Interpreters in Health Care. Accessed August 24, 2020. https://www.ncihc.org/assets/documents/publications/NCIHC\%20National\%20Standards\%20of\%20Practice.pdf.

Neubert, Albrecht. 2000. "Competence in Language, in Languages, and in Translation”. In Developing Translation Competence, edited by Christina Schäffner and Beverly Adab, 3-18. Amsterdam-Philadelphia: John Benjamins.

Nida, Eugene. 1964. Toward a Science of Translating, Leiden: Brill.

NJSC (New Jersey Supreme Court). 2016. Code of Professional Conduct for Interpreters, Transliterators, and Translators. Accessed August 11, 2020. https:// www.njcourts.gov/public/assets/langSrvcs/codeconduct.pdf

NRPSI (National Register of Public Service Interpreters). 2016. Code of Professional Conduct. Accessed August 14, 2020. https://www.nrpsi.org.uk/for-clients-of-interpreters/code-of-professional-conduct.html.

NSW HCIS (New South Wales Health Care Interpreter Services). 2014. Interpreting in healthcare. Guidelines for interpreters. Accessed August 19, 2020. https://www.slhd.nsw.gov.au/interpreters/pdf/Guidelines\%20for\%20HCIS. pdf.

Pokorn, Nike K., and Tamara Mikolič Južnič. 2020. "Community interpreters versus intercultural mediators. Is it really about ethics?". Translation and Interpreting Studies 15, no. 1: 80-107. Accessed August 10, 2020. https://doi. org/10.1075/tis.20027.koc.

RID (Registry of Interpreters for the Deaf). 2005. NAD-RID Code of Professional Conduct. Accessed August 10, 2020. https://rid.org/ethics/code-of-professional-conduct/.

Seleskovitch, Danica, and Marianne Lederer. 1984. Interpréter pour traduire. Paris: Didier Erudition.

SoM (= State of Mississippi). 2011. Code of Ethics for Court Interpreters. Accessed August 17, 2020. https://courts.ms.gov/aoc/courtinterpreter/ethics.pdf.

TransLaw. n.d. https://translaw.univie.ac.at/.

WCS (= Wisconsin Court System). 2014. Code OfEthics For Court Interpreters. Accessed August 17, 2020. https://www.wicourts.gov/services/interpreter/ethics. htm.

WRHA (Winnipeg Regional Health Authority). 2015. Code of Ethics and Standards of Practice for Interpreters. Accessed August 14, 2020. https://professionals.wrha.mb.ca/old/professionals/language/files/EthicsCode.pdf.

WSL (= Washington State Legislature). 2015. Code of Professional Conduct. Accessed August 13, 2020. https://app.leg.wa.gov/wac/default.aspx?cite=388-03-050. 